Thorax, 1980, 35, 496-499

\title{
Cryptogenic fibrosing alveolitis and lung cancer
}

\author{
M TURNER-WARWICK, M LEBOWITZ, B BURROWS, AND A JOHNSON \\ From the Cardiothoracic Institute, Brompton Hospital, London
}

ABSTRACT Lung cancer was found in $20(9 \cdot 8 \%)$ of 205 patients with cryptogenic fibrosing alveolitis $\stackrel{\vec{\omega}}{\circ}$ (CFA) or $12.9 \%$ of the 155 patients in this series followed to death. An excess relative risk of lung cancer $\overrightarrow{\times}$ of $14 \cdot 1$ was found in patients with CFA compared to the general population of comparable age and $\omega_{\bar{N}}$ sex, allowing for the lengths of follow-up of the CFA patients. The relative risk for male smokers $-V$ was (observed/expected) $15 / 1 \cdot 06=14 \cdot 2$, and for female smokers $(O / E) 2 / 0 \cdot 3=6 \cdot 7$. Only one male $\frac{\vec{C}}{\circ}$ and one female non-smoker had lung cancer. These data suggest that there is an excess risk of lung? cancer not wholly accounted for by age, sex, or smoking habit. The distribution of histological types? was not obviously different from that found in lung cancer without pulmonary fibrosis. Largec opacities suggestive of lung cancer were present at the time of first hospital attendance for symptoms relating to CFA in four of the 20 patients.Finger clubbing was present in $19(95 \%)$ compared with $\vec{\oplus}$ $116 / 185(63 \%)$ of those so far not developing cancer. There were no other clinical differences ato presentation. In particular, cancer was not found especially in those with longer survival from the onset of symptoms of CFA or with a greater initial radiographic change.

Lung cancers have been observed in relation to fibrotic scarring of the lung. ${ }^{1}$ Some of these are identified as in situ tumours and their histological type is that of an adenocarcinoma. Hyperplastic changes in the alveolar lining cells in cryptogenic fibrosing alveolitis are also well recognised, and patients with cryptogenic fibrosin alveolitis (CFA) and bronchiolar-alveolar cell carcinoma have been described. ${ }^{2}$

More recently Stack et $a l^{3}$ have reported five lung cancers among 96 patients but noted that the distribution of histological types was similar to that of patients without fibrosis. Murao, ${ }^{4}$ reporting a national survey in Japan, also found lung cancer in $9.7 \%$ of 176 patients.

While these reports quote overall figures which strongly suggest a considerable increase in lung cancer in CFA, there has been no detailed study to asses the excess cancer risk in relation to age, smoking habits, duration of follow-up, or other clinical features of CFA. The problem is a difficult one because it requires a fairly large number of patients followed for a substantial period.

\section{Methods}

A retrospective study has been undertaken of

Address for reprint requests: Professor Margaret Turner-Warwick, Cardiothoracic Institute, Brompton Hospital, Fulham Road, London SW? 6HP.
220 cases of CFA fulfilling the criteria used byo Turner-Warwick and Haslam ${ }^{5}$ seen at the Brompton Hospital between 1955 and 1973 and $\overrightarrow{\vec{O}}$ followed for a minimum of four years to January 1977 (range 4-21 years). The clinical features? including smoking habits and occupation, thera-o peutic response to corticosteroids, and survival data have been reported previously.

Follow-up data have been obtained either from the Brompton Hospital records or by correspond-0 ence with the physician in charge. All patients have been checked through the Register of Births and Deaths and causes of death obtained $₹$ from death certificates. Histological materialo has been reviewed by Dr Hinson at the Bromp- $D$ ton Hospital.

Of the 220 cases, 11 patients are believed to be alive because their deaths have not been recorded ${ }^{\circ}$ in the Births and Deaths Register and information $\tilde{O}^{-}$ is incomplete in four. These 15 patients have, therefore, been excluded from the present reporto which considers the 235 patients on whom detailedo follow-up information is available.

\section{Results}

Over the follow-up period 155 of the 205 ब patients have died (mean survival from presen-这 tation 3.4 years $\pm 3.7 \mathrm{SD}$ ). During the period of $\frac{\rho}{O}$ observation 20 patients have died from lung cancer $(9.8 \%$ of the population and $12.9 \%$ of 
Table 1 Observed and expected deaths from lung cancer by age and sex

\begin{tabular}{|c|c|c|c|c|c|c|c|c|c|}
\hline \multirow[t]{2}{*}{$\operatorname{Age}(y r)$} & \multicolumn{3}{|c|}{ Males } & \multicolumn{3}{|c|}{ Females } & \multicolumn{3}{|c|}{ Totals } \\
\hline & $\overline{O b}$ & $\operatorname{Exp}^{*}$ & $O / E$ & $\overline{O b}$ & $\operatorname{Exp}^{*}$ & $O / E$ & $\overline{o b}$ & $\operatorname{Exp}^{*}$ & $O / E$ \\
\hline $15-49$ & 0 & 0.02 & - & 1 & 0.01 & $\overline{20}$ & 1 & 0.03 & 33.3 \\
\hline 50-59 & 6 & 0.36 & $16 \cdot 7$ & 2 & $0 \cdot c 6$ & $33 \cdot 3$ & 8 & 0.42 & $19 \cdot 0$ \\
\hline $60-69$ & 7 & 0.73 & $9 \cdot 6$ & 0 & 0.07 & - & 7 & 0.80 & 8.75 \\
\hline $70+$ & 4 & $0 \cdot 15$ & $26 \cdot 7$ & 0 & 0.02 & - & 4 & 0.17 & $23 \cdot 5$ \\
\hline Totals & 17 & $1 \cdot 26$ & 13.5 & 3 & 0.16 & 18.7 & 20 & 1.42 & $14 \cdot 1$ \\
\hline
\end{tabular}

*Expected deaths calculated from the general population death rates per person years (that is, sum of years of follow-up for individuals in each age and sex group).

All relative risk ratios are significant by $\chi^{2}$ with Yates correction with $\mathrm{df}=1$ at $1 \%$ level.

the deaths). Lung cancer occurred in 17 of 137 men $(12.4 \%)$ and three of 18 women $(16.7 \%)$. The mean age at presentation was $62 \cdot 1 \pm 9 \cdot 7 \mathrm{SD}$ years and this was similar to that age of those without cancer. The mean age at death was 65.2 years $\pm 9 \mathrm{SD}$ and again this was similar to that of patients dying without clinical evidence of lung cancer. The relationship with age is set out in table 1 . There was a rising prevalence of cancer with increasing age $(p<0.03)$, and this was more marked for the men $(p<0.002)$. By contrast, all three women with cancer were less than 59 years old. The significant increase in men compared with women persists when adjusted for age $(p<0.02)$, but is eliminated when corrected for smoking (table 2). The difference between the prevalence of cancer in nonsmokers, $2 / 52(3.8 \%)$ compared with $17 / 145$ $(11.5 \%)$ of smokers (including ex-smokers) was not formally significant, $(\mathrm{p}<0.07)$; it became so, however, when adjusted for age $(p<0 \cdot 04)$.

The expected death rates from lung cancer in a population of men and women who do and do not smoke have been obtained from Doll. ${ }^{6}$ The ratio of observed cancers in CFA to the expected numbers in a sex and smoking matched "control" population, making allowance for the varying follow-up times, shows that the greatest excess of cancers occur in the smoking males (risk ratio 14.2) and smoking females (risk ratio 6.7). As lung cancer occurred in only one nonsmoking male and one non-smoking female, risk ratios in these groups are unreliable.

Large opacities suggestive of lung cancer were present at the time of first hospital attendance in four of the 20 patients. In the other 16 , the distribution of radiographic profusion scores at presentation was similar to that in those who did not develop lung cancer subsequently. Interestingly, 19 of the 20 cases had finger clubbing at presentation compared to $63 \%$ of the 185 cases who have not developed and died with lung cancer. The median survival from presentation to death from lung cancer was $3 \cdot 1 \pm 3 \cdot 1$ SD years compared to $3.4 \pm 3.8 \mathrm{SD}$ in those who died but did not develop cancer.

The histological type of the tumour was known in 15 instances. This was classified as squamous in nine, adenocarcinoma in two, alveolar cell carcinoma in two, undifferentiated in one, and giant cell in one.

\section{Discussion}

The frequency of deaths from lung cancer in our series $(12.9 \%)$ is similar to that found by Murao $^{4}(9.7 \%)$. The excess risk of death from lung cancer in CFA is of particular interest in view of the relatively short survival from first symptoms in so many of the cases. In a recent large series the mean duration of symptoms

Table 2 Observed and expected deaths from lung cancer in CFA by smoking and sex

\begin{tabular}{|c|c|c|c|c|c|c|c|c|c|c|c|c|c|c|}
\hline \multicolumn{5}{|l|}{ Males } & \multicolumn{5}{|l|}{ Females } & \multicolumn{5}{|l|}{ Totals } \\
\hline Number & $\begin{array}{l}\text { Years at } \\
\text { risk }\end{array}$ & $O b$ & Exp & $\overline{O / E}$ & Number & $\begin{array}{l}\text { Years at } \\
\text { risk }\end{array}$ & $O b$ & Exp & $\overline{O / E}$ & Number & $\begin{array}{l}\text { Years at } \\
\text { risk }\end{array}$ & $O b$ & $\operatorname{Exp}$ & $\overline{O / E}$ \\
\hline \multicolumn{15}{|c|}{ Non-smokers } \\
\hline \multirow[t]{2}{*}{14} & $62 \cdot 3$ & 1 & $0 \cdot 1$ & 10 & 38 & $229 \cdot 3$ & 1 & 0.6 & $1 \cdot 7$ & 52 & $291 \cdot 6$ & 2 & 0.7 & $2 \cdot 9$ \\
\hline & & \multicolumn{3}{|c|}{$\begin{array}{l}x^{2} 7.95 \\
(p<0.01)\end{array}$} & & & \multicolumn{3}{|c|}{$\begin{array}{l}x^{2} 0.28 \\
(p<0.5)\end{array}$} & & & & & \\
\hline & $9 \cdot 7$ \\
\hline \multicolumn{2}{|c|}{$116 \quad 508 \cdot 3$} & \multicolumn{3}{|c|}{$\begin{array}{l}\chi^{2} 183.5 \\
(\mathrm{p}<0.001)\end{array}$} & & & \multicolumn{3}{|c|}{$\begin{array}{l}\chi^{2} 11.35 \\
(p<0.001)\end{array}$} & & & & & 一 \\
\hline \multirow{2}{*}{\multicolumn{2}{|c|}{ Grand total }} & & & & & & & & & $197^{*}$ & $961 \cdot 1$ & $19+$ & $2 \cdot 46$ & $7 \cdot 7$ \\
\hline & & & & & & & & & & & & \multicolumn{2}{|c|}{$\begin{array}{l}x^{2} 160.04 \\
(p<0.001)\end{array}$} & \\
\hline
\end{tabular}


until presentation at hospital was two years and the median survival from this time was 47 months. Thus a substantial proportion of cases run a rapidly progressive course and it is even more significant that an excess death rate from cancer can be demonstrated. It is of course possible that the onset of fibrosing changes antedates the onset of symptoms by many years and that changes in the lung relevant to the development of cancer are of much longer duration than suggested by the history alone. This is unlikely to be the only explanation because a substantial proportion of our series had relatively slight radiographic changes on first attendance. Although the natural history of the condition is very varied, cases developing cancer were not found especially among those having a prolonged survival from the onset of symptoms of CFA.

Too few non-smokers have been studied to obtain accurate information but the evidence as it stands suggests that there is an excess risk $(\times 10)$ of cancer in males with CFA that cannot be accounted for by cigarette smoking alone $(\mathrm{p}<0 \cdot 01)$.

Excess lung cancer has been reported in other types of pulmonary fibrosis. In patients with asbestosis it has been calculated that at least $30 \%$ develop lung cancer and that there is at least an additive and possibly a multiplicative influence of cigarette smoking. ${ }^{7}$ Although the relative risk of cancer in patients with asbestosis - that is, pulmonary fibrosis-compared to those with equivalent exposure but without fibrosis is incomplete, it appears that cases without fibrosis may also have an excess incidence but to a much lesser extent. ${ }^{8}$ If this is so, it raises fundamental questions as to the relationship between exuberant collagen deposition in the lung and neoplastic change. That such an association might exist is further supported by the reports of cases of lung cancer in patients with systemic sclerosis. $^{9}$ In situ neoplastic change in the vicinity of fibrotic scars in the lung have been well described but are most frequently adenocarcinomas. The hyperplasia of alveolar lining cells observed in $\mathrm{CFA}^{10}$ might lead to a prediction of an increased incidence of alveolar cell carcinoma and although this has occasionally been reported, it was only seen in one of our cases. In general, however, the distribution of histological tyres was similar to that of lung cancer without fibrosis. The fundamental reason for predisposition to neoplastic change is obviously unknown. Alterations in the function of cells controlling the inflammatory response must be considered. If defective surveillance mechanisms are important, the finding of autoantibodies in $\underset{\vec{\rho}}{\vec{\rho}}$ a high proportion of cases with CFA-foro example, antinuclear antibody occurred in $45 \%$ 흥 of our series of 220 cases-is of interest. However, in the 18 patients with lung cancer, anti- $\widehat{\Phi}$ nuclear antibody was only found in five. Ao reduction of normal delayed hypersensitivitys responses in lung cancer has been used as. further evidence of a surveillance defect. How- $\vec{\omega}$ ever, the delayed skin type reactions are not in general reduced in CFA. ${ }^{11}$ Whether they are reduced in those cases developing lung cancer ${ }_{\omega}$ is unknown. More detailed work on subpopula- $-\pi$ tions of different functional types of $T$ cells is ${ }_{A}^{-}$ needed before such a defect can be excluded.\& Macrophage/lymphocyte interaction may beo important in surveillance mechanisms. Recent studies have shown that alveolar macrophagese in CFA are activated and appear to contain lesse lysosomal enzymes than controls. ${ }^{12}$ It is conceiv- $\overrightarrow{0}$ able that such continuous stimulation of macro-o phages perhaps by immune complexes ${ }^{13}$ alters their capacity to maintain a normal surveillanceo function.

Finally, the explanation of finger clubbing in relation to CFA, asbestosis, and lung cancer is o interest. The cause of this phenomenon is quite unknown but the observation that finger club- $\overrightarrow{0}$ bing was almost invariably present $(19 / 20)$ in cases having or subsequently developing cancer at the time of presentation, and often before. there was clinical evidence of tumour, is of interest and contrasts with the overall preva $\frac{\text { o }}{9}$ lence of finger clubbing in our series of $63 \%$ of patients who did not develop and die from lung cancer.

\section{References}

1 Spencer H. Pathology of the lung. Oxford Pergamon Press, 1968.

2 Jones AW. Alveolar cell carcinoma in idiopathid interstitial pulmonary fibrosis. $\mathrm{Br} \mathrm{J}$ Dis Chest 1970; 64:78-84.

3 Stack BHR. Choo-Kang YFJ. Heard BE. Thङ్ prognosis of cryptogenic fibrosing alveolitio Thorax 1972; 27:535-42.

4 Murao M. Idiopathic pulmonary fibrosis. Repor年 of the nationwide project research in Japare XIII World Congress on Diseases of the Chesit Chest 1980; (in press).

5 Turner-Warwick M, Haslam P. Antibodies i some chronic fibrosing lung diseases. I No\% organ-specific autoantibodies. Clin Allergy 1971 \& 1:83-95.

6 Doll $\mathrm{R}$. The age distribution of cancer in mars In: Engel A, Larsson T, eds. Cancer and agein 
Thule International Symposium. Stockholm: Nordiska Bokhandelus Forlag, 1968.

7 Berry G, Newhouse ML, Turok M. Combined effect of asbestos exposure and smoking on mortality from lung cancer in factory workers. Lancet 1972; 2:476-9.

8 Selikoff IJ, Churg J, Hammond EC. Asbestos exposure and neoplasia. JAMA 1964; 188:22.

9 Richards RL, Milne JA. Cancer of the lung in progressive systemic sclerosis. Thorax 1958; 13: 238-45.

10 Stack BHR, Grant IWB, Irvine WJ, Moffat MAJ. Idiopathic diffuse interstitial lung disease.
Am Rev Respir Dis 1965; 92:939-48.

11 Pierce R, Turner-Warwick M. Skin tests with purified protein derivative, Candida albicans and Trichophyton spp. in cryptogenic fibrosing alveolitis and asbestos related lung disease. Clin Allergy 1979; 10:229-37.

12 du Bois R. Alveolar macrophage enzymes and $\mathrm{C}_{3} \mathrm{~b}$ receptors in cryptogenic fibrosing alveolitis. Thorax 1979; 34:424.

13 Dreisin RB, Schwartz MI, Theofilopoulos AN, Stanford RE. Circulating immune complexes in the idiopathic interstitial pneumonias. $N$ Engl J Med 1978; 298:353-7. 